\title{
Assessment of Hyper-Viscoelastic Seismic Isolator Behaviour Using Finite Element
}

\author{
Emran Alotaibi ${ }^{1}$, Nadia Nassif ${ }^{1}$, Rami AISodi ${ }^{1}$, Sara Ayman ${ }^{1}$, Ibrahim Haj Fattouh ${ }^{1}$ \\ ${ }^{1}$ Department of Civil and Environmental Engineering, College of Engineering, University of Sharjah \\ P. O. Box 27272 Sharjah, Sharjah, UAE \\ U16200658@sharjah.ac.ae; U17105811@sharjah.ac.ae; U15200111@sharjah.ae.ac; U17200713@sharjah.ae.ac; \\ U18105826@sharjah.ac.ae
}

\begin{abstract}
Base isolation concept is a new technology on seismic control of structures. There are various types of seismic isolators that are used nowadays including elastomeric bearings isolators and sliding isolators. This paper describes the behaviour of a HyperViscoelastic rubber bearing isolator based on finite element (FE) software ANSYS. A 2D model consists of upper and lowers steel plates with a series of alternating layers of rubber and steel shim plates. Hysteresis graphs of the model was obtained from the software. This graph indicated the main characteristics of the isolator. Different stiffness coefficients were determined as well as the effective dumping. A detailed discussion was conducted at the end of this paper where the behaviour of the rubber bearing isolator was compared with the behaviour of a lead rubber isolator. Moreover, it has been proved that using Hyper-Viscoelastic Rubber would decrease the shear deformation amplitude (E), decrease of failure load and increase maximum deformation in the isolators.
\end{abstract}

Keywords: Rubber Bearing, Stiffness Coefficient, Hysteresis graph, Effective Dumping.

\section{Introduction}

In recent decades, base isolation concept has been promoted around the world to offer a high level of protection to structures from ground motions like earthquakes which could cause severe damages. To achieve such protection, different seismic devices called isolators are introduced at the foundation level allowing structures to perform properly during an earthquake. Seismic isolators provide adequate flexibility to structures. They have the main function of being extremely deformable under horizontal forces, but at the same time sufficiently stiff when loaded with vertical loads. In general, isolators are classified into two categories: elastomeric bearings and sliding bearings. Elastomeric bearing isolators are the most commonly used type for base isolation. The major types of elastomeric bearing isolators are: Low-Damping Natural Rubber Bearing and Lead-Rubber Bearing. As shown in Fig. 1, elastomeric bearing isolators consist of upper and lower steel plates with a series of alternating layers of natural, or synthetic, rubber bonded to intermediate steel shim plates. The rubber provides lateral flexibility while the steel provides vertical stiffness. A rubber cover is provided to protect the internal rubber layers and steel plates from environmental degradation. In some cases, a lead cylinder is installed in the centre of the bearing to provide high initial stiffness and a mechanism for energy dissipation. In this paper, a model was developed for simulating the behaviour and the main characteristics of a rubber bearing isolator using finite element (FE) software called ANSYS.

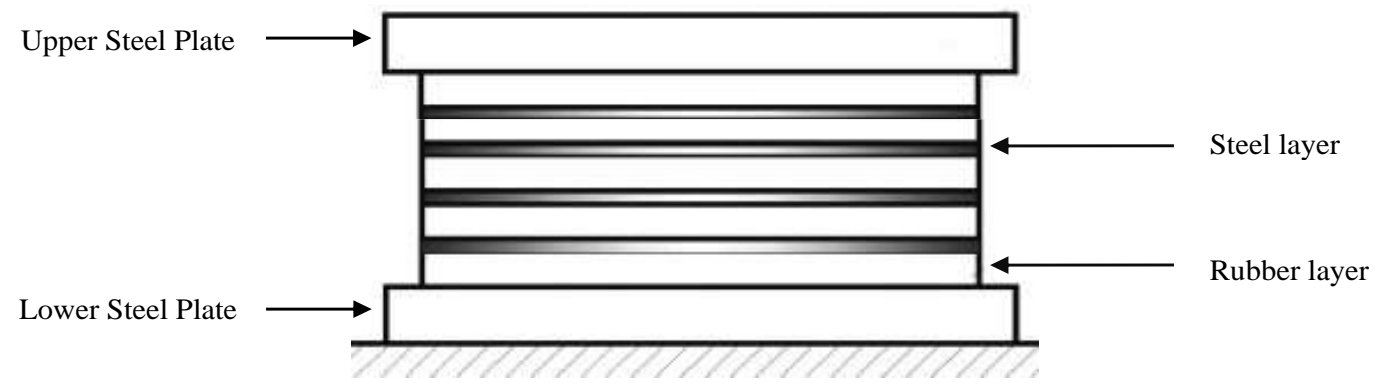

Fig. 1: Elastomeric Bearing Isolator. 


\section{Literature review}

Over the past years, seismic isolation rubber bearings in bridges and buildings have proven to be a very effective method for reducing earthquake forces. The amount of information regarding seismic isolation has grown exponentially. Detailed studies and researches have been fully established concerning this topic. Treloar [1] have investigated experimentally the behaviour of rubber types on different variables. His research concluded several models for explaining the rubber behaviour under loading, which was considered a base of modelling for several recent researches in this field. Ali et al., [2] elaborated on the modelling of rubber and lead passive-control bearings for seismic analyses. It was found that major decrease in earthquake applied forces along the bridge can be achieved with the energy dissipation devices when compared to using conventional methods. An analytical hysteresis model for elastomeric seismic isolation bearings was done by Kikuchi et al., [3] the model was applied to four different types of seismic isolation bearings, two of high-damping rubber bearing, one of lead-rubber bearing and one type rubber bearing. The model was validated by comparing dynamic analyses of two isolated structures results with earthquake simulator test results and it has shown good agreement between the analytical and experimental results. The theories and steps of baseisolated structure with rubber-bearing design were introduced by Tian et al., [4] the hysteretic curve show that structures with high damping rubber bearing and base isolation system can absorb the earthquake energy most effectively. Finiteelement analysis of laminated rubber bearing of building frame under seismic excitation was done by Ohsaki et al., [5] It was found that FE-analysis is indispensable tool for analysis and design of laminated rubber bearings. Incorporation of damping, softening property, and effect of temperature change for lead and high-damping rubber bearings remains to be investigated in future research. Amin et al. $[6,7,8]$ proposed an improved hyperelastic equation for shear regime and rubbers in compression, the equations' parameters were identified by the data from the rate-independent instantaneous experiments and equilibrium experiments, and the nonlinear viscous coefficient was introduced to represent the rate-dependent properties of rubbers.

\section{Methodology}

\subsection{Geometry Setup}

The behaviour of a rubber bearing isolator were analysed using ANSYS. ANYS software has been used in previous studies for simulating and understanding the behaviour of similar devices. The developed 2D model, as shown in Fig. 2 , consists of upper and lower steel plates with $1 \mathrm{~cm}$ thickness. Series of alternating layers of rubber and steel shim plates were located between the upper and the lower plates, both with length of $49 \mathrm{~cm}$. Each rubber layer has a thickness of 1.5 $\mathrm{cm}$ whereas the intermediate steel layers have a thickness of $0.6 \mathrm{~cm}$, with a total height of $20.3 \mathrm{~cm}$ and base length of $50 \mathrm{~cm}$.

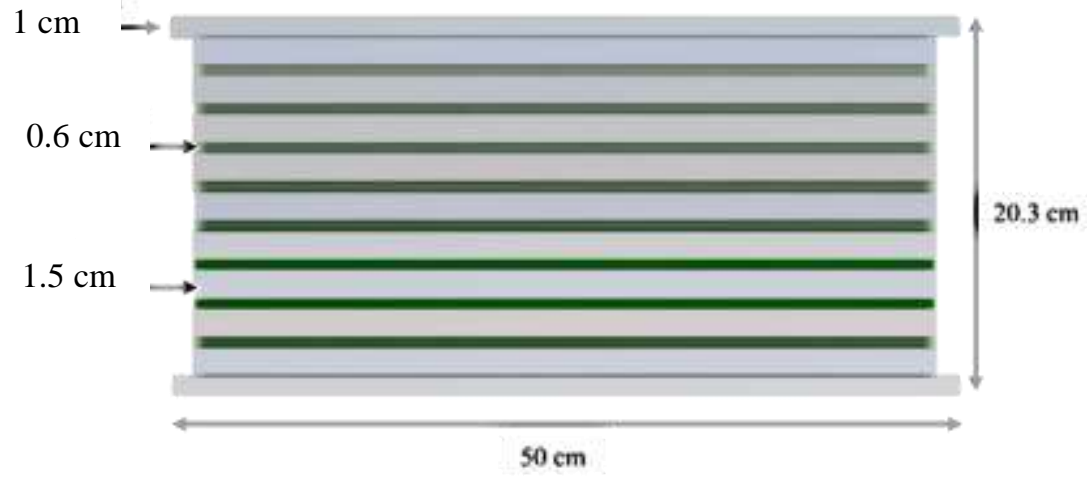

Fig. 2: Geometry of the rubber bearing model.

\subsection{Materials}

Different assigned material types are shown in table 1 for Steel layers. Rubber is viscoelastic and hyper-elastic material. Viscoelasticity is the property that shows both viscous and elastic characteristics when subjected to deformation. Viscous materials resist shear flow and strain linearly with time when a stress is applied, whereas elastic materials strain when stretched and quickly return to their original state once the stress is removed. Viscoelastic materials have elements of both properties. Because viscoelastic materials have the viscosity factor, they have a strain rate 
dependent on time. In hyper-elasticity behaviour, the stress-strain relationship can be defined as non-linearly elastic, isotropic, incompressible and generally independent of strain rate. The elastic deformation can be extremely large in the rubber. So, a compound material (hyper viscoelastic material) was assigned for each rubber layer and it consists of the Ogden model of the hyper-elastic behaviour and in addition to Prony series model of the viscoelastic behaviour.

Table 1: Selected Steel Properties.

\begin{tabular}{|l|c|}
\hline \multicolumn{1}{|c|}{ Property } & Value \\
\hline Density & $7850 \mathrm{Kg} / \mathrm{m}^{3}$ \\
\hline Coefficient of thermal expansion & $1.2 \times 10^{-05} \mathrm{C}^{-1}$ \\
\hline Temperature & $22 \mathrm{C}^{0}$ \\
\hline Tensile yield strength & $2.7 \times 10^{8} \mathrm{~Pa}$ \\
\hline Compressive yield strength & $2.7 \times 10^{8} \mathrm{~Pa}$ \\
\hline Tensile ultimate strength & $4.2 \times 10^{8} \mathrm{~Pa}$ \\
\hline
\end{tabular}

$\mathrm{Wu}$ [9] procedure for computing and analysing the hyper-viscoelastic material properties. Table 2 shows the hyper viscoelastic material properties that were computed and used in ANSYS software, it should be mentioned that constant values for $\boldsymbol{\alpha}$ s were taken from Treloar [1]. Prony series defines the changing in the material values (Shear modulus and bulk modulus) by time decaying.

Table 2: Hyper and Visco- elastic Material models and constants.

\begin{tabular}{|c|c|}
\hline \multicolumn{2}{|c|}{ Prony series model of the viscoelastic behaviour } \\
\hline Property & Value \\
\hline $\boldsymbol{\alpha a}_{\mathbf{1}}, \boldsymbol{\alpha}_{\mathbf{2}}, \boldsymbol{\alpha}_{\mathbf{3}}$ & 0.333 \\
\hline $\boldsymbol{t}_{\boldsymbol{1}}$ & $0.4 \mathrm{~s}$ \\
\hline $\boldsymbol{t}_{\mathbf{2}}$ & $0.2 \mathrm{~s}$ \\
\hline $\boldsymbol{t 3}$ & $0.1 \mathrm{~s}$ \\
\hline
\end{tabular}

\begin{tabular}{|c|c|}
\hline \multicolumn{2}{|c|}{ Ogden model of the hyper-elastic behaviour } \\
\hline Property & Value \\
\hline $\boldsymbol{\alpha}_{\mathbf{1}}$ & 1.3 \\
\hline $\boldsymbol{\alpha}_{\mathbf{2}}$ & 5 \\
\hline $\boldsymbol{\alpha}_{\mathbf{3}}$ & -2 \\
\hline $\boldsymbol{\mu}_{\mathbf{1}}$ & $1.9 \times 10^{6} \mathrm{~Pa}$ \\
\hline $\boldsymbol{\mu}_{\mathbf{2}}$ & $3598 \mathrm{~Pa}$ \\
\hline $\boldsymbol{\mu}_{\mathbf{3}}$ & $-29927 \mathrm{~Pa}$ \\
\hline
\end{tabular}

\subsection{Loading Settings}

For the analysis settings, a program-controlled mesh was applied on the model. The lower plate was fixed, and series of cyclic loading was applied on the upper plate, with displacement controls application. 15 load steps (1 second each) was used with displacements of 2, 5, 10, 15 and $20 \mathrm{~mm}$ in both directions as shown in Fig. 3.

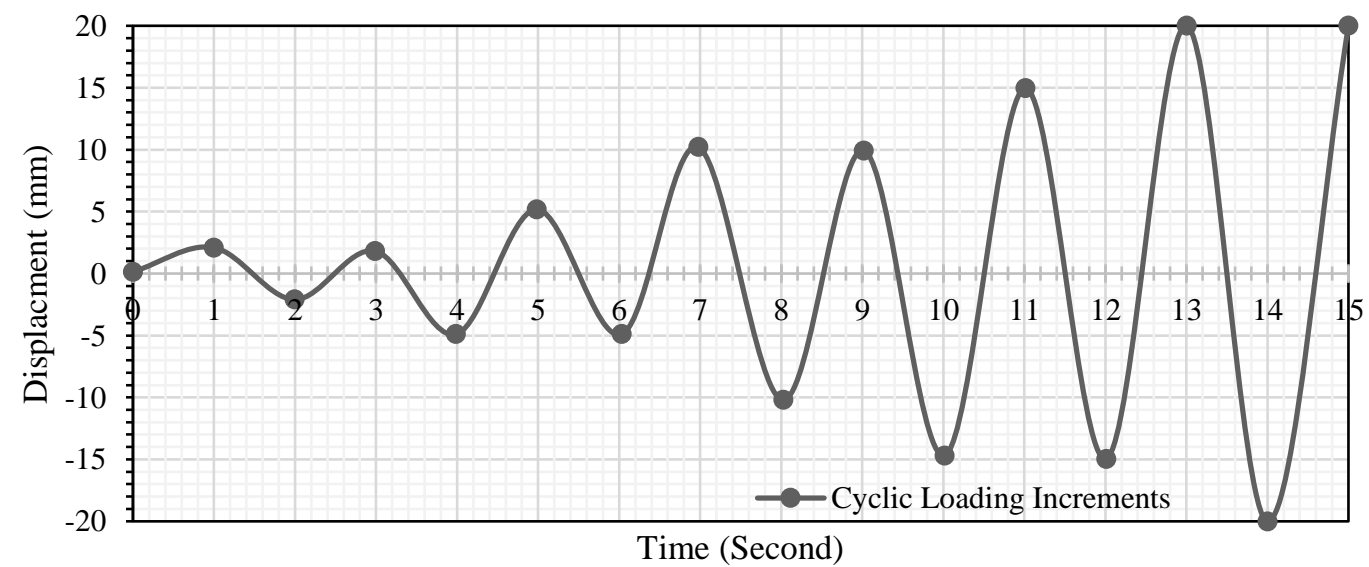

Fig. 3: Cyclic Loading. 


\section{Results and Discussion}

The program outputs have been analysed, and only parameters under study have been investigated. The hysteresis graph of the rubber bearing isolator was obtained, which shows the relationship between the force $(\mathrm{N})$ and the deformation $(\mathrm{mm})$ during loading and unloading, shown in Fig.4. The gradient of the loops represents the stiffness of the rubber, while the area between the curves show the energy absorbed and released during loading and unloading, respectively. Rubber absorbs more energy during loading than it releases in unloading, the difference is represented by the area of the hysteresis loop.

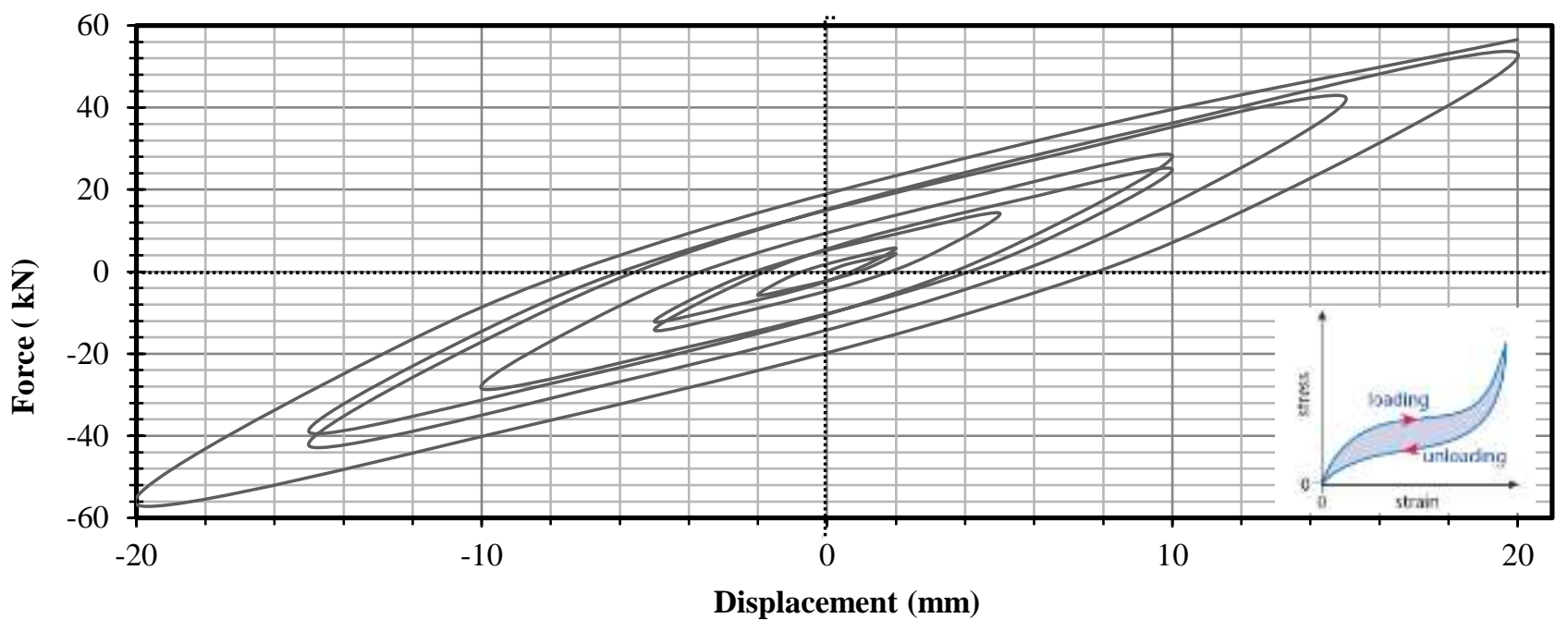

Fig. 4: Hysteresis Loop Graph.

The deformed shape of the rubber bearing isolator under the cyclic loading was obtained from ANSYS, as shown in the below graph that a maximum of $20 \mathrm{~mm}$ displacement was applied on the top of the Hyper-Viscoelastic Rubber Seismic isolator.
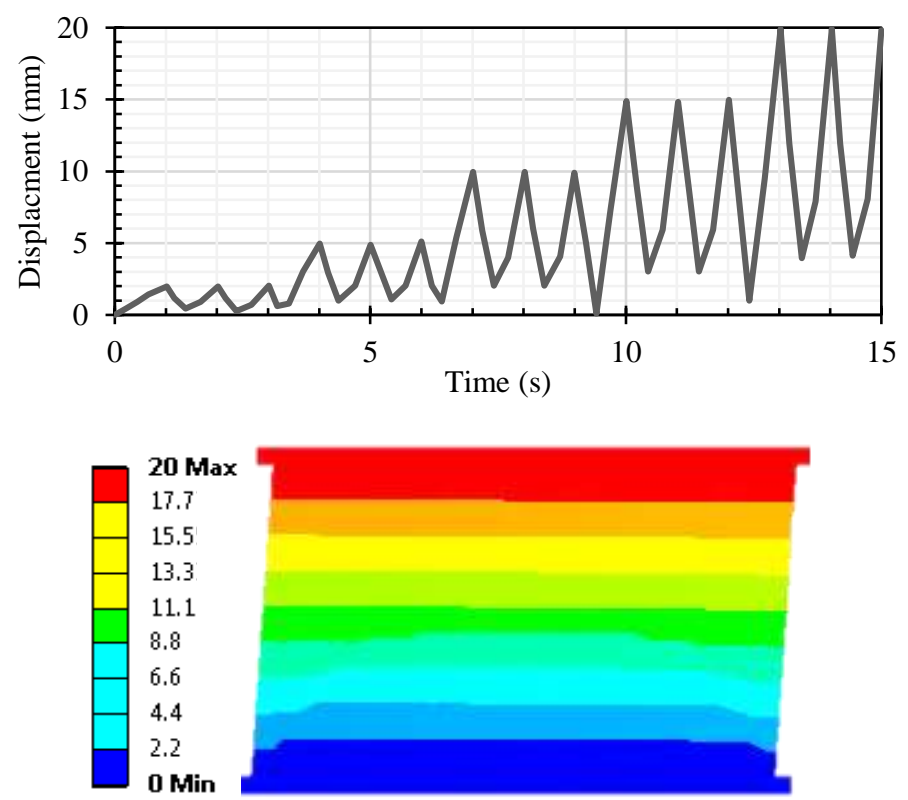

Fig. 5: Deformed shape and Highest Displacement with time for the rubber bearing isolator. 
Elastic stiffness coefficient $\left(\mathrm{K}_{\mathrm{e}}\right)$, plastic stiffness coefficient $\left(\mathrm{K}_{\mathrm{p}}\right)$ and effective stiffness coefficient $\left(\mathrm{K}_{\text {eff }}\right)$ were determined from the slope of the hysteresis loops for each loading cycle. In other words, each loading cycle coefficients were considered separately, as shown in Fig 6.

\section{Deformation (mm)}

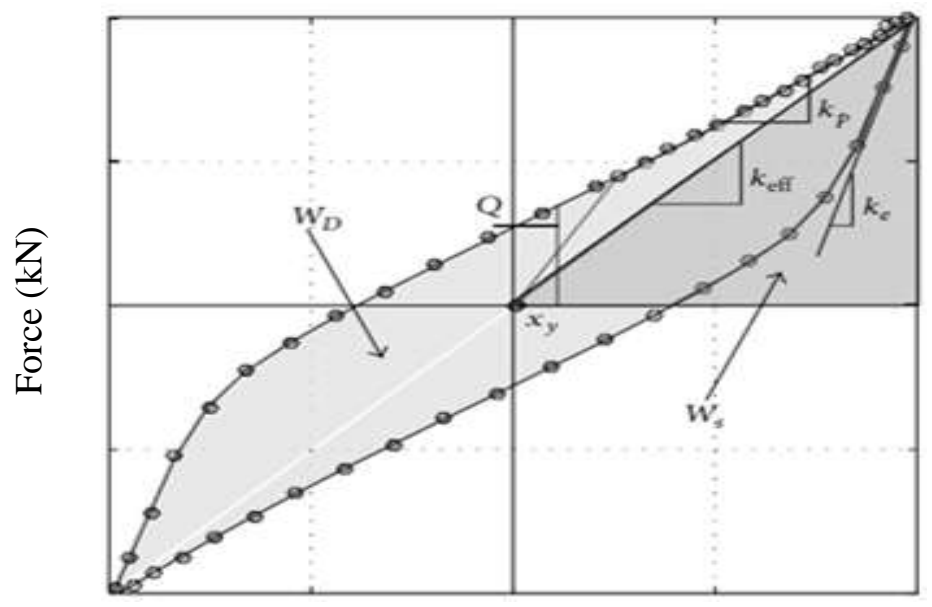

Deformation (mm)

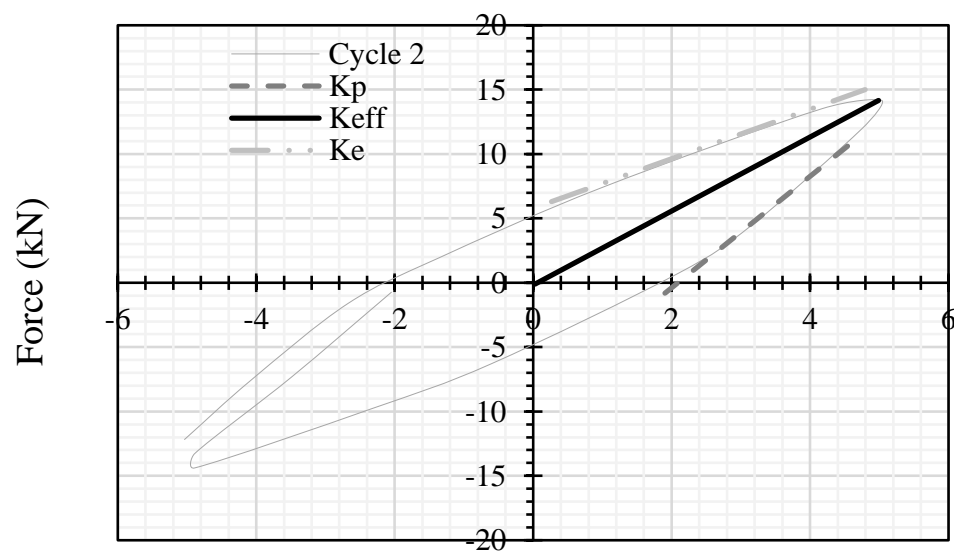

Deformation (mm)

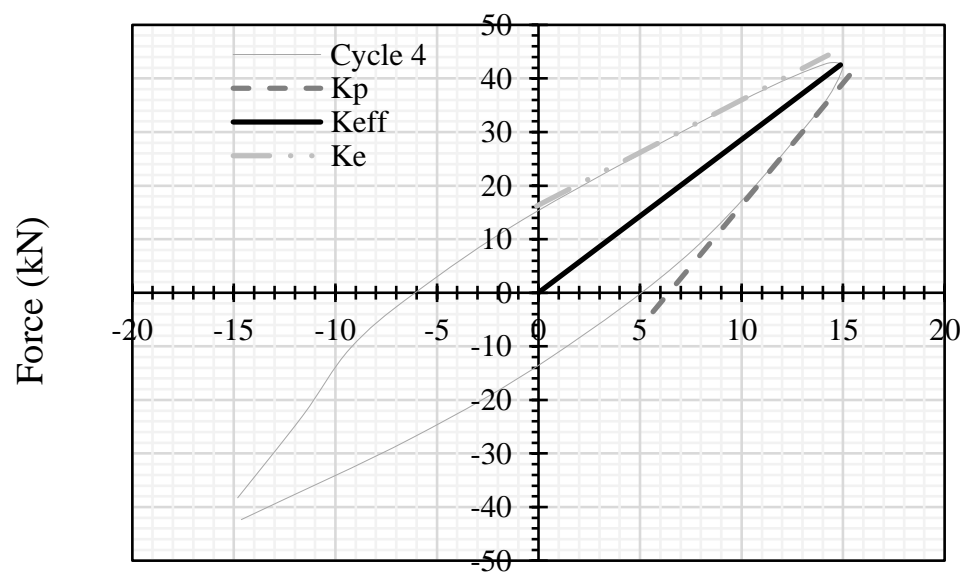

Deformation (mm)

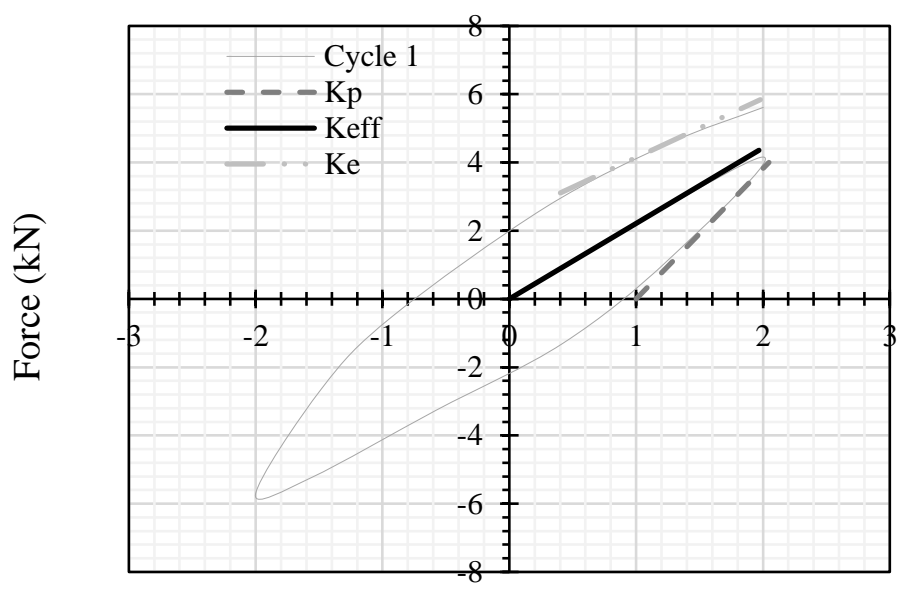

Deformation (mm)

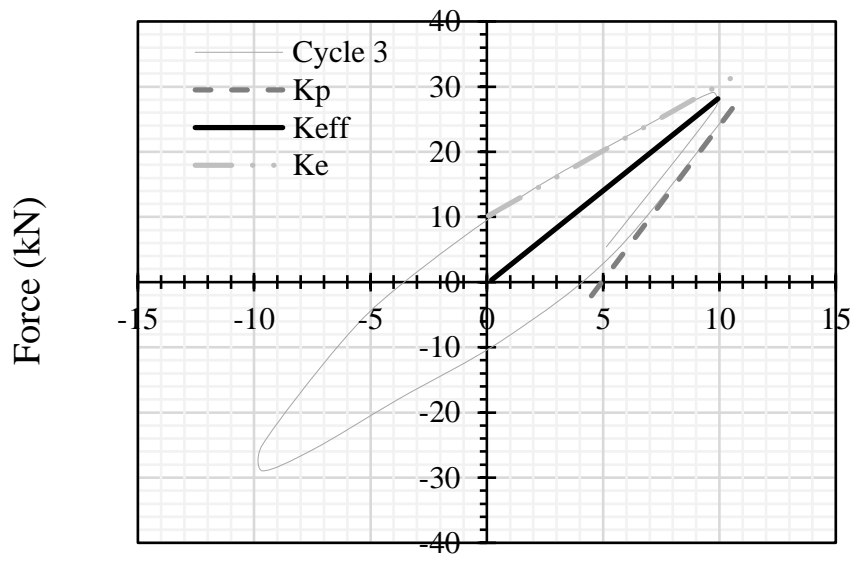

Deformation (mm)

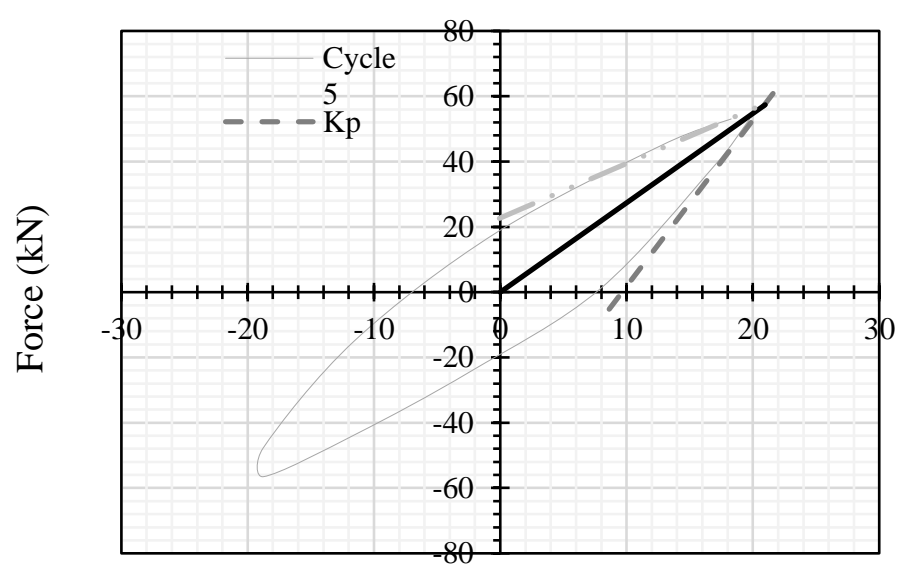

Fig. 6: a) Coefficients determination technique and b,c,d,e,f) Determination of Coefficients of different cycles 1 to 5. 
To assess the behavior of bearing isolator, different factors must be further calculated, which are as follows:

$$
\begin{gathered}
K_{\text {eff }}=\frac{F_{\text {max }}}{x_{\max }} \\
W_{s}=\frac{1}{2} k_{\text {eff }} * x^{2} \\
W_{D}=4 Q\left(x_{\max }-x_{y}\right) \\
\beta_{\text {eff }}=\frac{W_{D}}{4 \pi * W_{s}}
\end{gathered}
$$

Where $\mathrm{W}_{\mathrm{D}}$ is the area of the hysteresis loop, $\mathrm{Q}$ represents the energy dissipated per cycle and $\mathrm{W}_{\mathrm{s}}$ is the strain energy stored at maximum displacement. Table 3 shows the values of effective dumping of each loading cycle.

Table 3: Effective dumping results.

\begin{tabular}{|l|c|c|c|c|c|c|c||c|c|c|}
\hline & $\mathbf{K}_{\mathbf{e}}$ & $\mathbf{K}_{\mathbf{p}}$ & $\mathbf{F}_{\mathbf{m a x}}$ & $\mathbf{Q}$ & $\mathbf{X}_{\mathbf{y}}$ & $\mathbf{X}_{\max }$ & $\mathbf{K}_{\text {eff }}$ & $\mathbf{W}_{\mathbf{D}}$ & $\mathbf{W}_{\mathbf{S}}$ & $\boldsymbol{\beta} \mathbf{( \% )}$ \\
\hline Cycle (1) & 3.00 & 1.69 & 4.3 & 1.15 & 0.715 & 2 & 2.15 & 5.900 & 4.3 & 10.93 \\
\hline Cycle (2) & 4.24 & 1.69 & 14.2 & 4.50 & 2.243 & 5 & 2.80 & 49.630 & 35.0 & 11.29 \\
\hline Cycle (3) & 4.46 & 1.74 & 28.3 & 10.0 & 5.094 & 10 & 2.83 & 196.27 & 141.5 & 11.04 \\
\hline Cycle (4) & 4.50 & 1.73 & 42.6 & 15.8 & 6.200 & 15 & 2.84 & 556.03 & 319.5 & 13.86 \\
\hline Cycle (5) & 5.00 & 1.71 & 56.5 & 20.5 & 9.300 & 20 & 2.85 & 876.74 & 570.0 & 12.25 \\
\hline
\end{tabular}

Under the cyclic loading, the hysteresis curves present narrow zonal shape. With the increase of applied displacement, the hysteresis loops become bigger and their area $\left(\mathrm{W}_{\mathrm{D}}\right)$ increases as well. It is clear that all the loops are intertwined with almost the same slope. This means that the slopes of all hysteresis loop are parallel to each other's. On the other hand, the stiffness coefficients $\left(\mathrm{K}_{\mathrm{e}}, \mathrm{K}_{\mathrm{p}}, \mathrm{K}_{\mathrm{eff}}\right)$ shows a slight increase with the increase of the applied displacement. We can say that the stiffness coefficients $\left(\mathrm{K}_{\mathrm{e}}, \mathrm{K}_{\mathrm{p}}, \mathrm{K}_{\mathrm{eff}}\right)$ for all the loops are almost the same because of the behaviour of the slopes that are parallel in every loop.

It can be concluded that the energy dissipated per cycle increases with the increase of the applied displacement and this led to an increase in the effective dumping. A high damping coefficient will diminish the response and it will absorb the energy and reduce the undesired reaction. With the increase in energy dissipated, both $\mathrm{W}_{\mathrm{D}}$ and $\mathrm{W}_{\mathrm{S}}$ increase. From Fig. 6 the rate of increase in $\mathrm{W}_{\mathrm{D}}$ is more than $\mathrm{W}_{\mathrm{S}}$. This will result in a higher effective dumping.

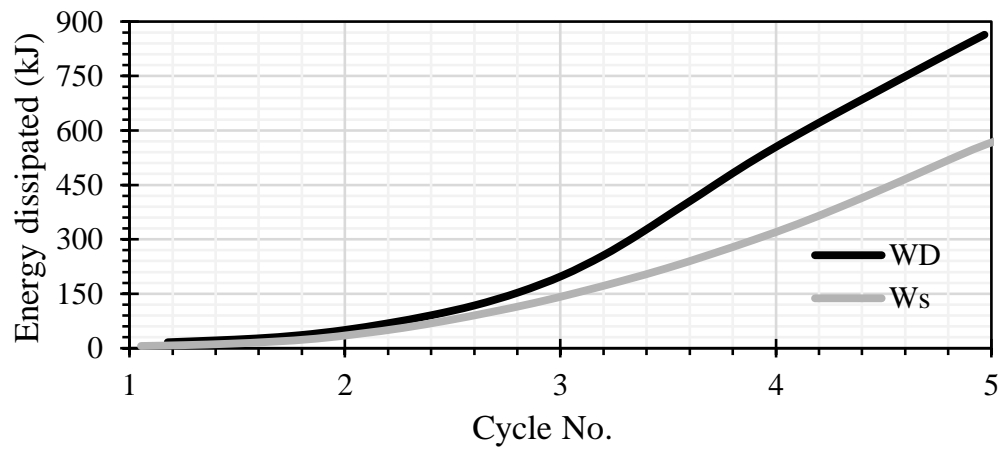

Fig. 7: Area of the hysteresis loop $\left(\mathrm{W}_{\mathrm{D}}\right)$ Energy stored at maximum displacement (Ws) with respect Cycle No.

The shear deformation amplitude $(E)$ represented the ratio of the displacement to the rubber layer thickness of the bearing. And the amplitudes were: 
Table 4: E values with changing of displacements.

\begin{tabular}{|c|c|}
\hline Displacement & E \\
\hline $\mathbf{2} \mathbf{~ m m}$ & $1.3 \%$ \\
\hline $\mathbf{5} \mathbf{~ m m}$ & $3.3 \%$ \\
\hline $\mathbf{1 0} \mathbf{~ m m}$ & $6.6 \%$ \\
\hline $\mathbf{1 5} \mathbf{~ m m}$ & $10 \%$ \\
\hline $\mathbf{2 0} \mathbf{~ m m}$ & $13.3 \%$ \\
\hline
\end{tabular}

If displacement is increased in magnitude till the failure of the rubber isolator, the stiffness coefficients $\left(\mathrm{K}_{\mathrm{e}}, \mathrm{K}_{\mathrm{p}}, \mathrm{K}_{\mathrm{eff}}\right)$ will not change because the hysteresis loops will still have the slopes. On the other hand, the area of each loop will increase, $\mathrm{W}_{\mathrm{s}}$ will increase also and this led to higher effective dumping. Failure occurs when the displacement $=52 \mathrm{~mm}$. At this stage, the protective rubber layer will be separated from the bearing body and expanding outwards, shown in Fig. 7.
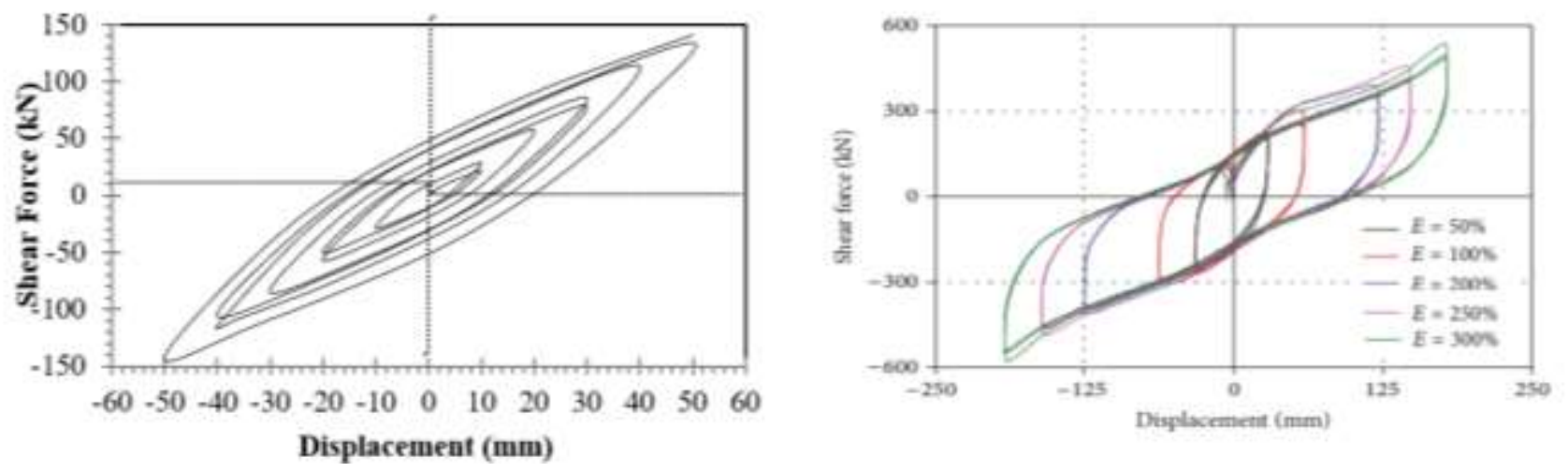

Fig. 8: a) Maximum hysteresis graph for Hyper-Viscoelastic Rubber Seismic Bearing Isolator, and b) LRB hysteresis graph from Yue Li with changing of shear deformation amplitude $(E)[6]$.

Comparing the behaviour of a rubber bearing isolator in Fig. 7a with Fig 7b obtained from Yue Li [6] analysis on lead rubber bearing (LRB), with changing the shear deformation amplitude $(E)$, the LRB isolators produce wider hysteresis loops due to their ability to dissipate higher amounts of energy, when increasing (E). The reason is mainly that the lead core in the lead rubber bearing began to dissipate energy in little deformation, while the elastomeric rubber bearing was still in its elastic deformation state. This indicates that using Hyper-Viscoelastic Rubber will decrease the shear deformation amplitude (E), with minor scarification of failure load and increasing in maximum deformation, which would be an important design parameter.

The strain using Ogden model could not exceed $200 \%$ of the strain, which is explained by detachment of steel layers with the rubber. Such outcome confirms with several researches (see Wi [9]). As recommendations, such outcomes shall be compared with experimental data to confirm the applicability of finite element analysis using same material properties.

\section{Conclusion}

Considering the behaviour of a rubber bearing isolator, a 2D model was developed using ANSYS software. The model consists of upper and lowers steel plates with a series of alternating layers of rubber and steel shim plates. Two types of materials were used in the model: Steel and hyper viscoelastic material. Hysteresis graph of the model was obtained from the software. This graph indicated the main characteristics of the isolator. From this graph the elastic stiffness coefficient $\left(\mathrm{K}_{\mathrm{e}}\right)$, plastic stiffness coefficient $\left(\mathrm{K}_{\mathrm{p}}\right)$ and effective stiffness coefficient $\left(\mathrm{K}_{\text {eff }}\right)$ were determined from the slope of the hysteresis loop for each loading cycle. Effective dumping was calculated as well. It was found that under the cyclic loading, the hysteresis curves present narrow zonal shape and the stiffness coefficients $\left(\mathrm{K}_{\mathrm{e}}, \mathrm{K}_{\mathrm{p}}, \mathrm{K}_{\mathrm{eff}}\right)$ for all the cyclic loops are almost the same. Also, the behaviour of the rubber bearing isolator was compared with LRB isolator, which indicated that the lead rubber isolators produce wider hysteresis loops due to their ability to dissipate higher amounts of energy. However, using 
Hyper-Viscoelastic Rubber shall decrease the shear deformation amplitude (E), with decreasing of failure load but increasing the maximum deformation as at deflection of $20 \mathrm{~mm}$ E reached to $13 \%$. It should be mentioned that the strain couldn't exceed the $200 \%$ using Ogden model, which needs further studies to be conducted using models and experiments.

\section{References}

[1] L. R. G. Treloar, "Stress-strain data for vulcanized rubber under various types of deformation," Rubber Chemistry and Technology, vol. 17, no. 4, pp. 813-825, 1944.

[2] H.-E. M. Ali and A. M. Abdel-Ghaffar, "Modeling of rubber and lead passive-control bearings for seismic analysis," vol. 121, no. 7, pp. 1134-1144, 1995.

[3] M. Kikuchi and I. D. Aiken, “An analytical hysteresis model for elastomeric seismic isolation bearings,” vol. 26, no. 2, pp. 215-231, 1997.

[4] T. X. Min and L. U. Ming, "Design of Base-Isolated Structure with Rubber-Bearing," presented at the 14th World Conference on Earthquake Engineering, 2008.

[5] M. Ohsaki, T. Miyamura, M. Kohiyama, T. Yamashita, M. Yamamoto, and N. Nakamura, "Finite-element analysis of laminated rubber bearing of building frame under seismic excitation," vol. 44, no. 11, pp. 1881-1898, 2015.

[6] A. F. M. S. Amin, M. S.Alam, and Y. Okui, "An improved hyperelasticity relation in modeling viscoelasticity response of natural and high damping rubbers in compression: experiments, parameter identification and numerical verification," Mech. Mater., vol. 34, pp. 75-95, 2002.

[7] A. F. M. S. Amin, S. I. Wiraguna, A. R. Bhuiyan, and Y. Okui, "Hyperelasticity model for finite element analysis of natural and high damping rubbers in compression and shear," J. Eng. Mech., vol. 132, pp. 54-64, 2006.

[8] A. F. M. S. Amin, A. Lion, S. Sekita, and Y. Okui, "Nonlinear dependence of viscosity in modeling the rate-dependent response of natural and high damping rubbers in compression and shear: experimental identification and numerical verification," Int. J. Plasticity., vol. 22, pp. 1610-1657, 2006.

[9] Y. F. Wu, A. Q. Li, H. Wang, "Parameter identification of hyperelastic and hyper-viscoelastic models," in the 2015 World Congress of Advances in Structural Engineering and Mechanics, 2015.

[10] Yue Li and Qiqi Wu, "Experimental Study on Friction Sliding Performance of Rubber Bearings in Bridges," Advances in Materials Science and Engineering, 2017. 